\title{
International Space Station Environmental Control and Life Support System Status for the Prior Year: $2010-2011$
}

\author{
David E. Williams ${ }^{1}$ and Jason R. Dake ${ }^{2}$ \\ NASA Lyndon B. Johnson Space Center, Houston, Texas, 77058 \\ and \\ Gregory J. Gentry ${ }^{3}$ \\ Boeing Space Exploration Division, Houston, Texas, 77058
}

\begin{abstract}
The International Space Station (ISS) Environmental Control and Life Support (ECLS) system includes regenerative and non-regenerative technologies that provide the basic life support functions to support the crew, while maintaining a safe and habitable shirtsleeve environment. This paper provides a summary of the U.S. ECLS system activities over the past year, covering the period of time between March 2010 and February 2011. The ISS continued permanent crew operations including the continuation of six crew members being on ISS. Work continues on the last of the Phase 3 pressurized elements, the commercial cargo resupply vehicles, and work to try and extend ISS service life from 2015 to no later than 2028.
\end{abstract}

${ }^{1}$ CxP Thermal/ECLS System Integration Group Co-Lead \& C3PO Thermal/ECLS Lead, 2101 NASA Parkway,

Mail Stop: EC6, AIAA Member.

2 ISS ECLS System Manager, 2101 NASA Parkway, Mail Stop: EC6

${ }^{3}$ ECLS Technical Lead, ISS ECLS, 3700 Bay Area BIvd, Mail Stop: HB2-40 